\title{
The literacy myth: literacy, education and demography ${ }^{1}$
}

\author{
Harvey J. Graff*
}

The new Encyclopedia of Language and Education defines 'literacy myth' thus:

"Literacy Myth refers to the belief, articulated in educational, civic, religious, and other settings, contemporary and historical, that the acquisition of literacy is a necessary precursor to and invariably results in economic development, democratic practice, cognitive enhancement, and upward social mobility [...] Literacy in this formulation has been invested with immeasurable and indeed almost ineffable qualities, purportedly conferring on practitioners a predilection toward social order, an elevated moral sense, and a metaphorical 'state of grace' [...] Associated with these beliefs is the conviction that the benefits ascribed to literacy cannot be attained in other ways, nor can they be attributed to other factors, whether economic, political, cultural, or individual. Rather, literacy stands alone as the independent and critical variable. Taken together, these attitudes constitute what Graff has called "the Literacy Myth."

Adherents of the literacy myth eschew social, cultural, political, and economic contexts, including criticism of different conceptions of literacy and epistemologies of its research. Conviction in "strong' theories that link possession of literacy directly to major cognitive, economic, political, social, and cultural transformations is another element.

The assumed link between literacy and economic success is one of the cornerstones of western modernisation theories, and the last century and a half witnessed what we may call the globalisation of the literacy myth. Literacy-

* Harvey J. Graff, Department of English, The Ohio State University, 546 Denney Hall, 164 West 17th Avenue, Columbus, OH, 43210, USA. Email: graff40@humanities.osu.edu

An extended version of this discussion appeared in the Journal of Social History, vol. 43 (Spring, 2010): 635-661 as "The Literacy Myth at Thirty". See also my The Literacy Myth: Literacy and Social Structure in the Nineteenth-Century City, New York and London, Academic Press, Studies in Social Discontinuity Series, 1979; The Legacies of Literacy: Continuities and Contradictions in Western Society and Culture, Bloomington, Indiana University Press, 1987; The Labyrinths of Literacy, Pittsburgh, University of Pittsburgh Press, Composition, Literacy, and Culture Series, 1995; "Literacy, Education, and Fertility, Past and Present: A Critical Review," Population and Development Review 5(1979): 105-140; and Graff, H. J. (ed.) Literacy and Historical Development, editor and contributor, Carbondale, Southern Illinois University Press, 2007. 
usually in one or another form of the literacy myth - takes pride of place, at least symbolically, in many designs for rapid economic and social development. In some cases, the inspiration lies in an image, not a clear and accurate vision, of an earlier developing west. In others, it may be an elaborate blueprint. In some cases, the imperative or stimulus is internal to the target state, in Tokugawa Japan, Russia and the Soviet Union or China, among prominent cases. In others, especially after World War II, impetus, 'aid', or detailed plan was exported from the west by development specialists in universities, NGOs, government agencies or the United Nations. Both could be embedded in national literacy campaigns. Both derived to some extent from myths about the place of literacy in modernisation.

Emphasising that two-thirds of all illiterate adults were women, UNESCO Deputy Secretary General Louise Frechette in 2003 declared literacy a prerequisite for a "healthy, just and prosperous world": "When women are educated and empowered, the benefits can be seen immediately: families are healthier; they are better fed; their income, savings and reinvestments go up. And what is true of families is true of communities - ultimately, indeed, of whole countries." Here is the literacy myth in action.

Part of what makes these assumptions about the benefits of literacy a myth is that they are not universally true. Often, though, they are partly true.

As a recognisable field of literacy studies emerged, earlier expectations (and theories) that literacy's contribution to shaping or changing nations, and the men and women within them, was universal, unmediated, independent and powerful have been quashed, in theory and in history (if not in all practice). Literacy - that is, literacy by itself-is now seldom conceptualised as independently transformative. To the contrary, we now anticipate and recognise its impact to be shaped by specific historical circumstances, complicated rather than simple, incomplete or uneven, interactive rather than determinative, and mediated by a host of other intervening factors of a personal, structural, or cultural historical nature, rather than universal. In other words, literacy is a historical variable, and it is historically variable.

Yet literacy or at least a minimal amount of education is presumed to be necessary and sufficient for overcoming poverty and surmounting limitations rooted in racial, ethnic, gender and religious differences. Implicit in this formulation is the belief that individual achievement may reduce the effects of ascribed social and structural inequalities. Despite such expectations, that literacy and education can and have been used to stimulate democratic discourse and practices, literacy has been used to foster political repression and maintain inequitable social conditions.

Historical research and interpretation challenge nineteenth and twentieth century images and understandings of the importance of literacy and, conversely, the negative consequences of its absence. Our notions about the relationships of literacy to such major processes as schooling, long-distance migrations, 
adaptation and assimilation to new urban environments and chances for advancement are changing. Social class, ethnicity, race, gender and geography emerge as key factors but usually in more complicated and contradictory ways than we long presumed. Literacy's power and influence were seldom independent of other determining and mediating factors.

In The Literacy Myth, the book, I joined Roger Schofield and others in questioning a direct connection between popular literacy levels, as evidence of skill and/or cognition and rates of literacy's spread, and the main lines of historical economic growth and development. That connection lay at the heart of the literacy myth. We argued for a lesser and a less direct connection between literacy and, in particular, industrialisation, compared with, for example, literacy's more direct relationships with commercial capitalism. I urged greater attention to the importance of workplace experience and learning on the job, on the one hand, and, on the other, of schooling's impact on attitudinal, behavioural and other noncognitive attributes. No one denied the importance of literacy and education. But they were configured as less direct and independent relationships. For formulations with human capital at their core, and for proponents of the literacy myth, such scepticism verged on sacrilege.

For the past and the present, debate continues about literacy and other levels of education as forms of or direct contributions to human capital. But what of the fate of the literacy myth in more recent decades and the present? Has postindustrialism's dependence on advanced technology and the knowledge economy's dependency on advanced education proved it correct or made it obsolete?

Hacker and others point to complications in the relationships among education, high technology and jobs. While the income gap between college graduates and others has widened, the "outsized sums accruing to the very top tiers" account for a great deal of the difference, not the earnings of graduates as a whole. The intellectual emphasis in much of the college curriculum and the job skills mandated for the workforce do not match well. Even more important is the fact that an enlarging chasm exists between the rising numbers of graduates in technological fields and the more limited number of jobs expected to be available for them. For example, the estimated number of engineers graduating by 2016 is four times greater than the expected number of new jobs (Mitch 2005, Mitch 2009, see also Vincent 2000, Goldin and Katz 2008, Becker and Woessmann (forthcoming). For a very different economic analysis, see Pritchett 2006). ${ }^{2}$ Many of the fastest growing jobs cluster on the low road. In one analysis, jobs in the lowest quartile of earnings will account for about 40 per cent of growth in the top thirty occupations. These include many food and service workers, clerks, guards,

\footnotetext{
For a very interesting argument for an increasing value of literacy, specifically of writing, as a development of the so-called knowledge economy or society, see Brandt (2003, 2004, and 2005), Katz and Stern (2006), Henwood (2003), Madrick (2007), and Hacker (2009). Hacker notes that the United States can not expect to repeat the doubling of degrees in the 1960s.
} 
nurses and computer software engineers. Katz and Stern summarise: "Less than 25 per cent of the top thirty jobs will require a bachelor's degree or higher; 54 per cent will require short on-the-job training. Outside the top thirty, 25 per cent of new jobs will require a bachelor's degree or more-but almost 50 per cent will require no more than short-to-medium-term on-the-job training." Seventy-five per cent will require less than an associate's degree. Poorly paid, dead-end jobs that lack benefits appear even within the most technologically sophisticated industries.

Joining a canon that I set out to challenge and change in the 1970s and 1980s admittedly is sometimes strange or strained. So, too, was the need especially in The Literacy Myth's earlier years to reject charges that, as a critic of normative perspectives on literacy (in that discourse, a revisionist), to some persons, I was, somehow, anti-literate or a traitor to the educators' cause and investment in claims of the promises of schooling. This continues to strike me as odd and unwarranted. Socio-cultural myths, like the literacy myth, are never wholly false. Otherwise they would not gain acceptance or hegemony.

I never claimed that there was no relationship between literacy and economic success, income and literacy skill, labour force attainment and literacy, and occupational change and literacy. To the contrary, we emphasised their complexity, variability and contradictoriness in relationships among key factors, and in more general explanatory and interpretive terms that shape expectations, theory and policy. Never did we allege that literacy was unimportant.

To argue that literacy has been accorded the status of myth is not to discount the importance of reading and writing, or to suggest that these are irrelevant in the contemporary world. That is clearly not the case. However, we may contrast the literacy myth, and its seamless connections of literacy to individual and collective advancement, with more complex and often contradictory lessons that are consistent with historical and recent literacy development and practice.

Yet the central, critical role of myth is often misunderstood: Such attitudes about literacy represent a 'myth' because they exist apart from and beyond empirical evidence that might clarify the actual functions, meanings and effects of reading and writing. Like all myths, the literacy myth is not so much a falsehood but an expression of the ideology of those who sanction it and are invested in its outcomes. Contradicting popular notions, myth is not synonymous with the fictive or the false. By both definition and means of cultural work, myths cannot be wholly false. For a myth to gain acceptance, it must be grounded in at least some aspects of perceived reality and cannot explicitly contradict all ways of thinking or expectations.

The vagueness of such definitions allows for conceptions of literacy that go beyond what has been examined empirically, thus investing literacy with the status of myth.

In the literacy myth, reading and writing are a universal good and ideologically neutral. However, the history of literacy and schooling demonstrates that no mode or means of learning is neutral. Literacy is a product of the specific 
circumstances of its acquisition, practice and uses, and so reflects the ideologies that guide them. School literacy, in particular, is neither unbiased nor the expression of universal norms of reading and writing. It reflects the structures of authority that govern schools and their societies.

The literacy myth is powerful, resilient, flexible, complex and historically rooted. It is also marked by its potential to work constructively and progressively but at the same time with limiting or negative force, for both individuals and groups. For some persons, their history and faith joined with the literacy myth's promise of the benefits of reading and writing to both push and pull many people to literacy. For others, the contradictions were too great, the opportunities to gain and practice reading and writing too limited, the payoffs neither frequent nor clear.

Only by grounding definitions of literacy in specific, contextualised and historical particulars can we avoid conferring on literacy the status of myth.

In contemporary popular discourse, literacy is represented as an unqualified good, a marker of progress and a metaphorical light making clear the pathway to progress and happiness. The opposing value of 'illiteracy', in contrast, is associated with ignorance, incompetence and darkness.

Experiences of learning literacy include cognitive and non-cognitive influences. This is not to suggest that literacy should be construed as any less important, but that its historical roles are complicated and historically variable. The views that literacy's importance and influences depend on specific social and historical contexts, which, in effect, give literacy its meanings; that literacy's impacts are mediated and restricted; that its effects are social and particular; that literacy must be understood as one among a number of communication media and technologies replace an unquestioned certainty that literacy's powers were universal, independent and determinative.

Myths can be expressions of collective desires, of the many and the few, of their differential agency and power. Perhaps the literacy myth expresses a hope that literacy alone is enough to end poverty, elevate human dignity and promote a just and democratic world. A less benign reading is that the literacy myth is a means through which to obscure the causes of social and economic inequities in Western society at least by attributing them to the literacy or illiteracy of different peoples. In such a reading, literacy is a symptom and a symbol.

What do these insights into the misunderstood role of literacy imply for both the more general and the more specific role of formal educational attainment?

We must take care to distinguish these two phenomena.

While mass public schooling today presents the most common route for individuals learning to read and write, the diversity of learners, including adult learners, in Europe and North America demands flexible understandings and pedagogies for literacy development. There is no single road to developing literacy. Different societies and cultures have taken different paths toward rising levels of literacy. 
Nevertheless the literacy myth may dampen our expectations for educational attainment defined in arbitrary thresholds of formal schooling. If we cannot assume the acquisition of literacy to constitute a transformative leap, how much less, for example, must this be the case for the transition from Grade 6 to Grade $7 ?$

At the same time, schooling represents more than just the acquisition of literacy, and may therefore confer certain benefits even if or when the latter does not.

Numeracy, to take one key example, is among the multiple modes of literacy. In The Literacy Myth, I offered anecdotal evidence that workers unable to read alphabetic texts were able to count and that colours were sometimes substituted for alphabetic markers. In exciting new research, Jorg Baten and his colleagues argue that numeracy may have been more broadly based than literacy in western Europe than in the east, even by 1600 . They conceptualise it as a form of human capital. Its contribution to economic growth and development may have exceeded that of popular literacy, especially in advance of both mass schooling and industrialisation (Graff 2009, Chapter 5, A'Heam et al. 2009. Thanks to David Mitch for telling me about this work).

Recognition of the literacy myth does not, therefore, lead to any automatic conclusion with respect to the present debate. Other myths surround biological sex as well as age, without diminishing their utility as dimensions of disaggregation in demographic research.

One important difference, however, is that in contrast to age and sex, education typically has an assessment of value built into our expectations. In light of the literacy myth, there will usually be a tendency to assume that a population with a higher attainment profile is 'better', with all the troubling consequences such an evaluation entails, when it might not necessarily be more 'successful', even in limited economic categories.

The idea of treating educational attainment as an individual's single most important socio-economic characteristic, not in response to its proven discriminatory power in a given time and place bound population, but a priori, is an act of myth-making par excellence.

I suspect that, as with literacy, the effects of schooling are historically contingent. This question extends to the effects of schooling on demographic behaviour.

The consequences of accepting uncritically the literacy myth are continuing to misunderstand the nature of literacy, its development, uses and potentials to foster or inhibit social and economic development. The same complication, even contradiction, applies if we replace 'literacy' with 'education'. I believe that the unconditional elevation of educational attainment to a defining demographic variable would only serve to limit our understanding of the complex role schooling plays in demography. 


\section{References}

A'Hearn, B., J. Baten, and D. Crayen. 2009. "Quantifying quantitative literacy: Age heaping and the history of human capital." Journal of Economic History 69(03): 783808.

Becker, S. O. and L. Woessmann. 2009. "Was Weber wrong? A human capital theory of Protestant economic history." Quarterly Journal of Economics 124(2): 531-596.

Brandt, D. 2003. "Changing Literacy." Teachers College Record 105: 245-260.

Brandt, D. 2004. "Drafting U.S. literacy." College English 66: 485-502.

Brandt, D. 2005. "Writing for a living: Literacy and the knowledge economy." Written Communication 22: 166-197.

Goldin, C. and L. F. Katz. 2008. The Race Between Education and Technology. Harvard University Press, Cambridge, Massachusetts.

Graff, H. J. 1979. The Literacy Myth: Literacy and Social Structure in the NineteenthCentury City. New York and London, Academic Press. Studies in Social Discontinuity Series.

Graff, H. J. 1979. "Literacy, Education, and Fertility, Past and Present: A Critical Review." Population and Development Review 5: 105-140.

Graff, H. J. 1987. The Legacies of Literacy: Continuities and Contradictions in Western Society and Culture. Bloomington, Indiana University Press.

Graff, H. J. 1995. The Labyrinths of Literacy. Pittsburgh, University of Pittsburgh Press, Composition, Literacy, and Culture Series.

Graff, H. J. (ed.) 2007. Literacy and Historical Development. Carbondale, Southern Illinois University Press.

Graff, H. J. 2010. "The literacy myth at thirty." Journal of Social History 43(3): 635-661.

Hacker, A. 2009. “Can we make America smarter?” New York Review of Books, 30 April.

Henwood, D. 2003. After the New Economy. The New Press, New York, London.

Katz, M. B. and M. J. Stern. 2006. One Nation Divisible: What American Was and What It Is Becoming. Russell Sage Foundation, New York.

Madrick, J. 2007. "Goodbye, Horatio Alger." The Nation, 5 February.

Mitch, D. 2005. "Education and Economic Growth in Historical Perspective," EH.Net Encyclopedia, ed. Robert Whaples, July 26, 2005. Accessed at: «http://eh.net/encyclopedia/article/mitch.education».

Mitch, D. 1999. "The role of education and skill in the British industrial revolution.” In: J. Mokyr (ed.) The British Industrial Revolution: An Economic Perspective. West View Press, Boulder, Colorado, pp. 241-279.

Pritchett, L. 2006. "Does learning to add up add up? The returns to schooling in aggregate data." In: E. A. Hanushek and F. Welch (eds.) Handbook of the Economics of Education, Vol. 1.Elsevier, North-Holland, Amsterdam, pp. 635-695.

Vincent, D. 2000. The Rise of Mass Literacy: Reading and Writing in Modern Europe. Polity press, Oxford, 2000. 